\title{
Monitoring Displaced People in Crisis Situations Using Multi-temporal VHR Satellite Data During Humanitarian Operations in South Sudan
}

\author{
Petra Füreder ${ }^{1}$, Stefan Lang $^{1}$, Edith Rogenhofer ${ }^{2}$, Dirk Tiede ${ }^{1}$ and Andreas Papp ${ }^{2}$ \\ ${ }^{1}$ Department of Geoinformatics - Z_GIS, University of Salzburg, Austria petra.fuereder@sbg.ac.at \\ ${ }^{2}$ Ärzte ohne Grenzen/Médecins Sans Frontières (MSF), Austria
}

Full paper double blind review

\begin{abstract}
Natural disasters, changing environmental conditions, and violent regional conflicts are main drivers for population displacement. Worldwide, more than 50 million people are displaced. One tragic example of huge displacement due to a conflict situation is the Republic of South Sudan, where 1.7 million people have been forced to flee their homes since December 2013. Most of them found refuge in numerous spontaneous settlements, either camps for internally displaced people (IDPs) within the country, or refugee camps in neighbouring countries. In such crisis situations, humanitarian organisations often do not have access to the areas and only have vague information on the location and amount of affected population. Using very high resolution (VHR) satellite imagery, rumours about displaced people can be generally verified or falsified, while for areas where displaced people gather, information on amount and spatial distribution of dwellings can be extracted for population estimates. Such information assists in planning services like health care or vaccination campaigns and planning of needed infrastructure like boreholes, latrines or hospitals. Camps in the setup and construction phase are often highly dynamic and require regular monitoring. Beyond this emergency phase, specific information is also requested by organisations involved in camp management in all other phases of humanitarian crisis response, i.e. in the care and maintenance phase, as well as the repatriation phase.
\end{abstract}

\section{Introduction}

\subsection{EO for Monitoring Displaced Population}

Natural disasters, changing environmental conditions, and violent regional conflicts are main drivers for population displacement. Most of the displaced people find refuge in dedicated camps or temporary settlements. Especially camps for internally displaced people (IDPs) are often highly dynamic in nature, confronting humanitarian organisations with situations where fast decisions need to be made, while solid management structures are not yet in place. These circumstances make reliable information a valuable good, in particular in the emergency phase where basic services (food, water, shelter, health care, etc.) are to be provided in an effective and rapid manner. Efficient response in terms of humanitarian aid can only be accomplished when reliable information about the on-site situation is available. Still, the required mission-critical information is often not available in a proper time-

GI_Forum - Journal for Geographic Information Science, 1-2015.

(c) Herbert Wichmann Verlag, VDE VERLAG GMBH, Berlin/Offenbach. ISBN 978-3-87907-558-4.

(c) ÖAW Verlag, Wien. ISSN 2308-1708, doi:10.1553/giscience2015s391. 
frame by local actors on the ground. Information extraction from very high resolution (VHR) satellite imagery can provide important indications of human presence such as amount and type of dwelling structures.

Within a cooperation agreement with Médecins Sans Frontières (MSF) Austria, since 2011, Earth observation (EO)-based information products are provided on demand. This includes information on amount and spatial distribution of different dwelling types, the analysis of internal camp structure analysis, and the temporal dynamics of the camp. Most of the requests emerge in the initial (emergency) phase, makeing them highly time-critical. As by now, more than thirty analyses were provided to MSF and other humanitarian organisations for refugee and IDP camps in ten countries, mainly in Eastern Africa. The usability of the EO-based information is continuously assessed by and refined according to the feedback provided by team members on the ground and in headquarters.

\subsection{The Particular Case of South Sudan}

Due to the restarting of the armed conflict in South Sudan in December 2013, hundreds of thousands of people were forced to flee their homes in eight states in South Sudan. While the majority of displaced people (around 1.3 million) stayed within the country as IDPs, about 500,000 people fled to neighbouring countries (UNHCR 2014). The IDPs stayed in camps or sought refuge in UN compounds throughout the country. EO-based information on affected population was requested for four sites in South Sudan and two refugee camps in Ethiopia (see figure 1). The requests allowed a narrow time frame of around one week from data acquisition to information delivery. Since then, one of the IDP camps, Minkaman, was regularly monitored during the setup and construction phase; another site (Melut) was analysed in two timeslots, and another three sites (Renk, Paloich, Kule/Tierkidi) once.

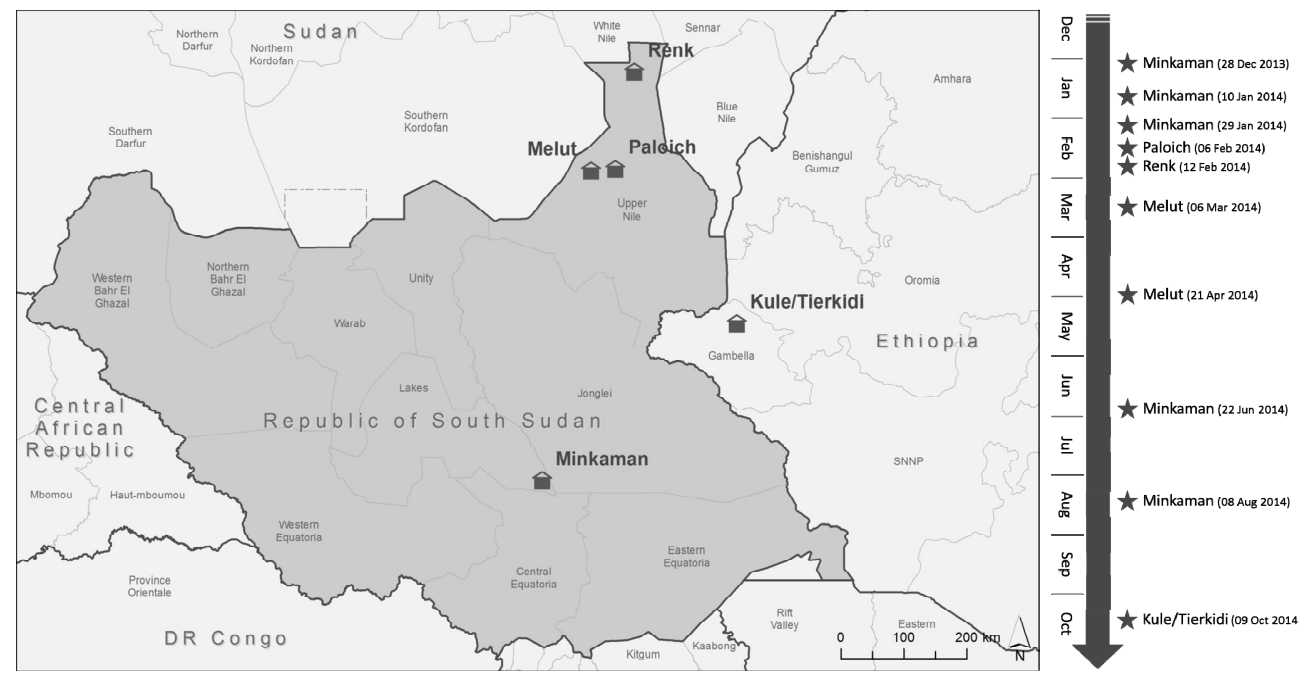

Fig. 1: Overview of analysed sites and time-line of corresponding data acquisition in a time frame from Dec 2013 until Oct 2014 
Minkaman. IDPs from the surrounding countries started to arrive in Minkaman village, near the city of Bor, in mid December 2013. The arrival of the IDPs at Minkaman, with formerly 7000 inhabitants, resulted in a collapse of the existing health system, as it was impossible to cover the needs of the IDPs and the host population. Initially, the influx of IDPs was roughly 500 persons per day until the camp population reached its peak of approx. $80,000-85,000$ in February 2014, since when the population has remained fairly stable. To aid the intervention and to fine-tune the activities, the operational responsible for MSF requested the camp to be analysed at different times, to get a better understanding of the population movement, as well as the indicators on population numbers.

Melut. With the ongoing fighting in Malakal and Baliet county, and in the area south of Melut, large numbers of people were forced to flee, arriving from January onwards in the area of Melut. Several camps were established, initially in school compounds, as well as within the UN compound. Due to the steady influx of IDPs, which increased to more than 15,000, two camps - Denthoma 1 and Denthoma 2 were established close to Melut. The responsible MSF emergency coordinator in the area requested EO-based information for Denthoma for population estimates, as the considerable number of transiting IDPs made it quite difficult to get an overview of the number of people staying in the camps.

Renk and Paloich. At the same time as the influx of IDPs into Melut, fighting and consecutive displacement was reported in other areas of the Upper Nile. The teams in the field received information that 9000 IDPs are gathered in Renk, and approximately 10,000 IDPs fled to Paloich. Active fighting continued in the area, so it was not feasible to send exploration teams through these areas to assess the situation and confirm the number of IDPs in the area. To prepare for the time when access to Renk and Paloich was possible, and plan sufficient supplies, the team requested analysis of current satellite images to confirm the presence of IDPs in these areas.

Kule and Tierkidi (Gambella region, Ethiopia). With fighting erupting in Jonglei, Upper Nile and Unity state in South Sudan, people were forced to flee to Ethiopia. By April 2014, at least 1000 refugees arrived in Ethiopia per day, in addition to the 80,000 already living in several refugee camps (Tierkidi, Letchuor, Itang) in the Gambella region. By mid June, additional camps were opened in the area to accommodate the refugees. By September 2014 Hepatitis E broke out in the Kule and Tierkidi camps. EO-based analysis of the camps was requested to support epidemiological monitoring, and to get a better understanding of the camp, the distribution of dwellings within the area, as well as the population figures of the camp.

\subsection{Satellite Data Used}

For the camps Minkaman and Denthoma 1 and 2, very recent archive imagery was available (see table 1), which is not usually the case. New image acquisition is a critical factor for timely delivery of results, especially in areas with cloudy weather conditions. At this time of emergency, other organisations were acquiring data for nearby areas, which - as a side effect - also improved the data situation for these sites. This fact, combined with favourable weather conditions, made a very timely availability of adequate satellite data possible.

In addition to the EO-data, data from OpenStreetMap (roads) was integrated. For Minkaman and Kule data on camp zones was available. 
Table 1: Overview of input data and pre-processing steps

\begin{tabular}{|c|c|c|}
\hline Site & EO Data (pre-processing) & $\begin{array}{l}\text { Acquisition Date \& Type } \\
(A=\text { Archive; } \\
\text { N = New Acquisition) }\end{array}$ \\
\hline Minkaman & $\begin{array}{l}\text { WorldView-2, orthorectification, pan-sharpening } \\
\text { (HCS) co-registered to [1] }\end{array}$ & $\begin{array}{l}\text { 2013: [1A] } 28 \text { Dec / 2014: } \\
\text { [2A] 10 Jan / [3A] } 29 \text { Jan / } \\
{[4 N] 22 \text { Jun / [5N] } 08 \text { Aug }}\end{array}$ \\
\hline \multirow{2}{*}{$\begin{array}{l}\text { Melut } \\
\text { (Denthoma } \\
1 \text { and 2) }\end{array}$} & GeoEye-1, orthorectification, pan-sharpening (IHS) & 06 Mar 2014 [N] \\
\hline & $\begin{array}{l}\text { WorldView-2, pan-sharpening (HCS), orthorectifica- } \\
\text { tion, co-registration }\end{array}$ & 21 Apr 2014 [A] \\
\hline Paloich & $\begin{array}{l}\text { WorldView-2, orthorectification, pan-sharpening } \\
\text { (HCS) }\end{array}$ & 06 Feb $2014[\mathrm{~N}]$ \\
\hline Renk & $\begin{array}{l}\text { WorldView-2, orthorectification, pan-sharpening } \\
\text { (HCS) }\end{array}$ & 12 Feb $2014[N]$ \\
\hline $\begin{array}{l}\text { Kule and } \\
\text { Tierkidi }\end{array}$ & $\begin{array}{l}\text { WorldView-2, orthorectification, pan-sharpening } \\
\text { (HCS), mosaicking }\end{array}$ & 09 Oct $2014[\mathrm{~N}]$ \\
\hline
\end{tabular}

\section{Methodology}

\subsection{Object-based Dwelling Extraction and Manual Post-processing}

We developed, applied, and continuously improved rule-sets for automated dwelling extraction using object-based image analysis (OBIA, see e.g. BLASCHKE 2010), over several years, for various refugee and IDP camps, mainly located in Eastern Africa (c.f. LANG et al. 2010, TIEDE et al. 2010, TIEDE et al. 2013). We thereby distinguish and extract different dwelling types (if applicable, depending on the camp situation, geographical setting, and season), according to their spectral reflectance, their geometry in terms of size and form, as well as their contextual relations. For the refugee/IDP camps in South Sudan and Ethiopia, we distinguished up to six different dwelling types (see figure 2).
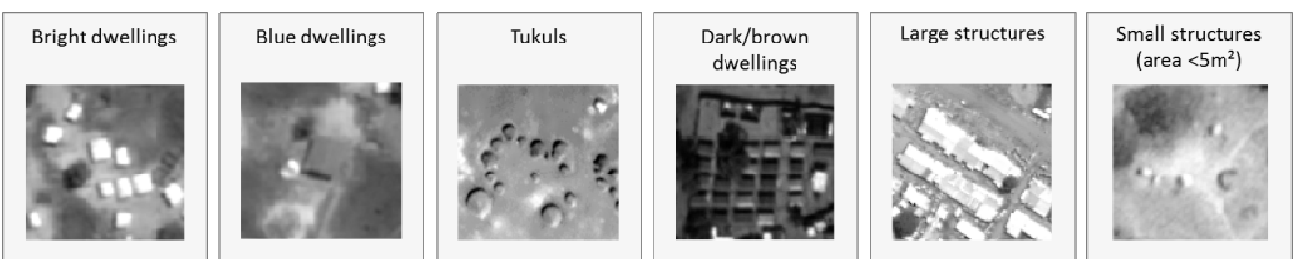

Fig. 2: Dwelling types detected on VHR data for the analysed refugee/IDP camps in South Sudan and Ethiopia 
The Minkaman camp site was initially unplanned, and most people were sheltering under trees with no proper shelter. There were some tents and some informal shelters with sheets and sticks. On the basis of this information, also very small, bright objects were considered in the analysis as potential makeshift structures.

As the automation is still limited for very complex situations (concerning dwelling types and density, as well as image quality and season, c.f. FüREDER et al. 2014), and reliable results are important in an operational context, the results are checked by visual interpretation, and manually refined whenever required. For this process, we developed a toolbox to support the manual post-processing (TIEDE et al. 2013). The toolbox is programmed in Cognition Network Language (CNL) and available in eCognition Architect. The manual refinement is supported by automated regular tiling of the area, portioning the postprocessing work and keeping track of areas already reviewed. Post-classification and object-refinement tools like re-classification, (re-)segmentation of target objects or classes to reduce time-consuming digitising of polygonal features - or post-processing (clean-up, dissolve, export), are made available through an easy to use graphical user interface (GUI).

\subsection{Object-specific Change Detection}

Changes of single dwellings are analysed between two points in time using an objectspecific change analysis approach. Based on extracted dwellings of the initial image (time $t_{0}$ ) and a comparison with the results of the following image (time $t_{1}$ ), a rule-set is used to classify stable objects (detected in $t_{0}$ and $t_{1}$ image, at least partly overlapping), removed objects (only detected in $t_{0}$ image), and new objects (only detected in $t_{1}$ image) (see figure 3 ).

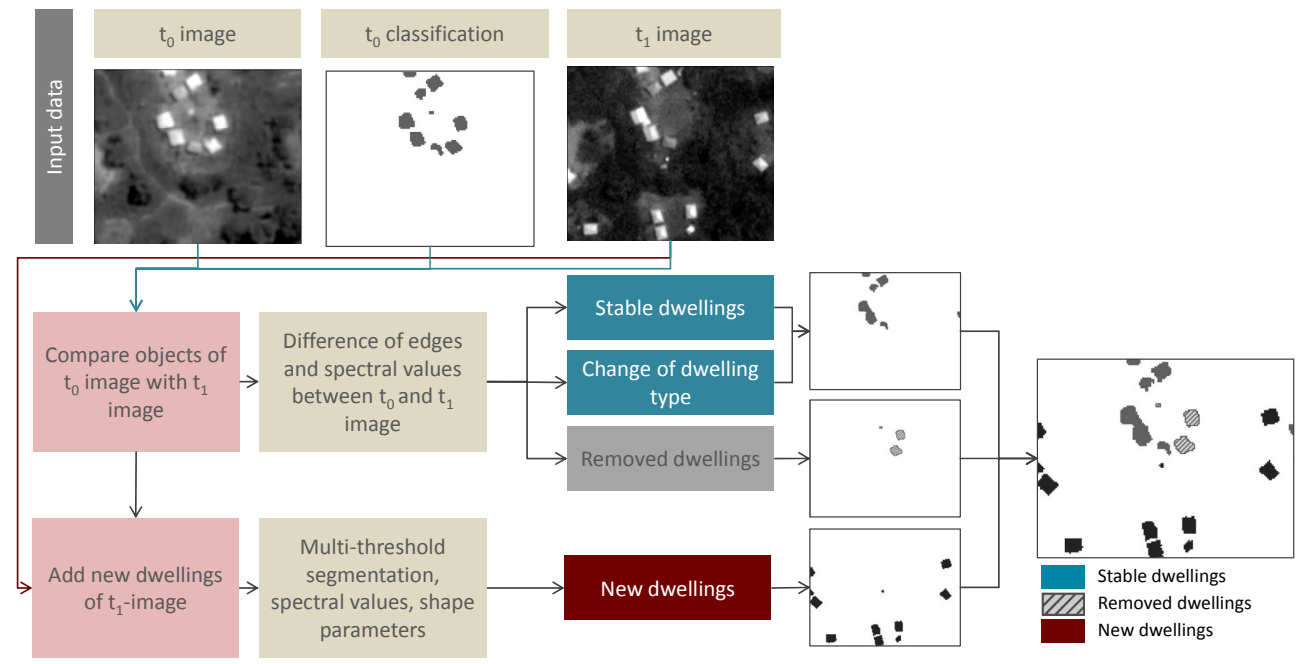

Fig. 3: Workflow for object-specific change analysis

The classification result of the $t_{0}$ image is included in the analysis of the $t_{1}$ image. Dwellings with a considerable difference between $t_{0}$ and $t_{1}$ regarding spectral information and edges are classified as removed dwellings. Dwellings may also be reclassified if the dwel- 
ling type is changing (e.g. from white to blue plastic sheeting). This object-specific change detection is especially useful for camps in the setup phase with high dynamics.

\subsection{Added value products}

Although information on single dwellings is important for planning logistical infrastructure and services (e.g. health care, water supply etc.), it is often required to aggregate this information for a more generalised interpretation (see figure 4). A dwelling density map using kernel density calculations provides a 'hot spot' map, indicating where people are concentrating within a camp. As planning is often done on the basis of camp zones, dwelling and dwelling distribution statistics can also be aggregated to these administrative camp management areas. Information on concentrations of specific dwelling types (e.g. makeshift shelters versus tents) may indicate camp areas undersupplied at a given point in time. Major changes between two timeslots, and the corresponding change patterns within the camp, can be grasped much easier if changes in the number of dwellings between $t_{0}$ and $t_{1}$ are aggregated to larger regular reporting units like grids or hexagons. Using the information of single dwellings, and additional GIS data, distance-based analyses are performed as requested (e.g. how many dwellings are within a certain distance to latrines, schools etc.).

\section{Emergency Phase \\ Care and maintenance Phase}
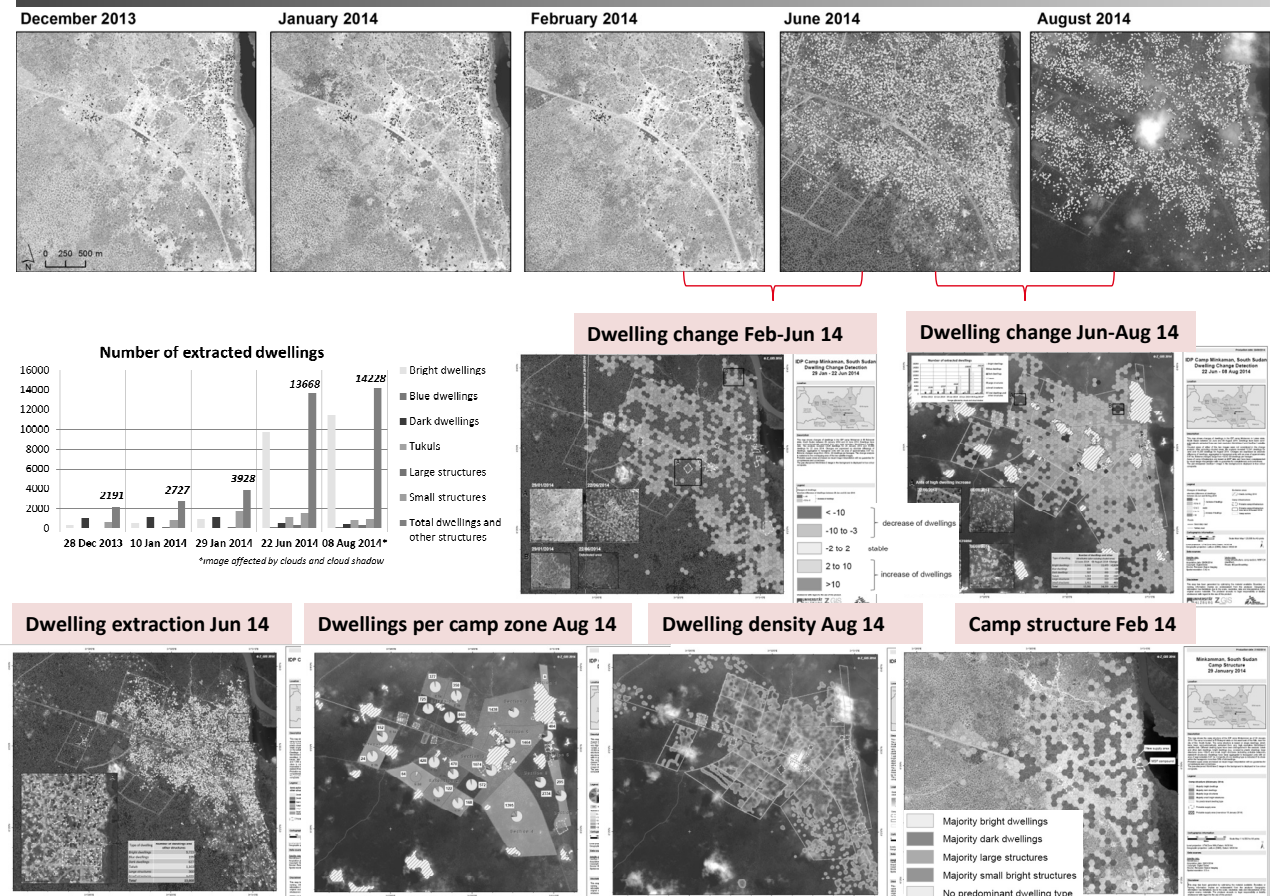

Dwellings per camp zone Aug 14

Dwelling density Aug 14

Camp structure Feb 14
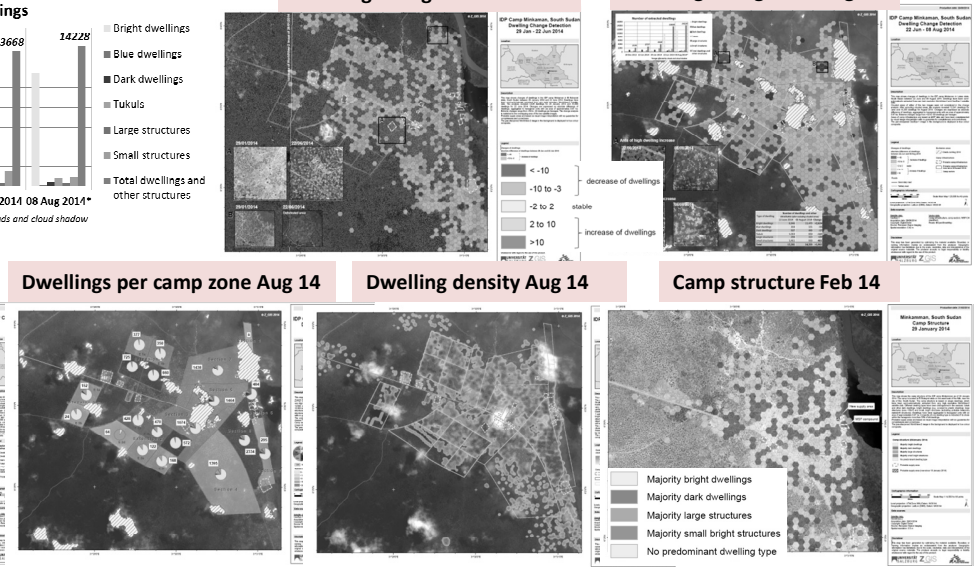

Fig. 4: Dwelling extraction and added value products for Minkaman camp, which was monitored from the emergency phase to the care and maintenance phase 


\section{Results}

\subsection{Results of extracted dwelling numbers}

For the IDP camp Minkaman, a series of five WorldView-2 satellite images (see table 1) was analysed, ranging from the setup phase to the care and maintenance phase. Observing the construction of a new camp from scratch revealed an enormous increase of dwellings (from around 2,000 in December 2013 to more than 14,000 in August 2014). It also showed a change of camp structure from more makeshift shelter to pre-fabricated tents (see figure 5). Four dwelling types were distinguished over the entire time frame: bright dwellings, dark dwellings, large structures (area $>50 \mathrm{~m}^{2}$ ), and small structures (area $<5 \mathrm{~m}^{2}$ ). For the two latest images blue dwellings and tukuls (traditional round huts) were additionally distinguished.
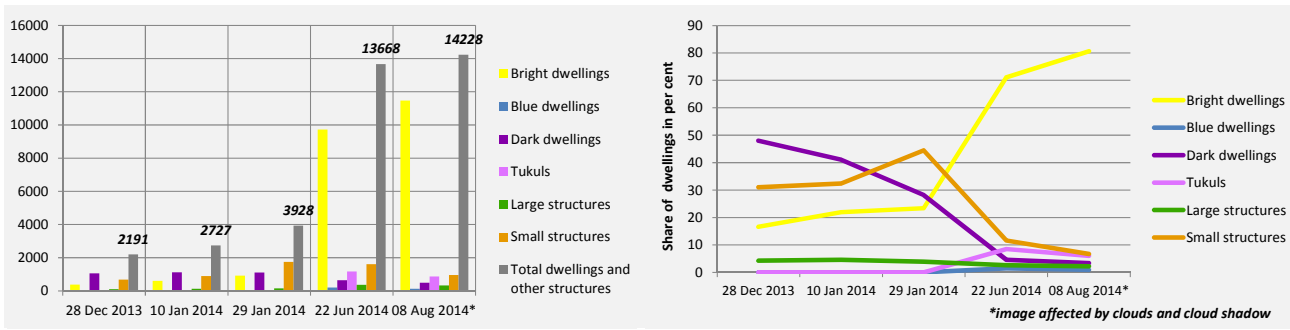

Fig. 5: Development of amount of extracted dwellings (left) and share of dwelling types (right) of Minkaman camp between the five time stamps analysed

For the IDP camps Denthoma 1 and 2 near Melut, two points in time were analysed (06 March 2014 and 21 April 2014) to monitor the evolution of the camps. Five different dwelling types were distinguished: traditional dwellings, dwellings with white/blue plastic sheeting, large/small structures. For the analysis of the second time stamp, an additional class residential dwellings - was introduced, as the camps were already expanding into preexisting villages. The number of dwellings for both camps increased from 1,927 in March, to 2,963 in April. For the refugee camps Kule and Tierkidi in Ethiopia, the degree of automation was quite high, due to the high contrast of dwellings and regular arrangement, with only few attached dwellings. Five dwelling types were distinguished in the analysis: bright $d$ wellings (emergency shelters/UNHCR tents), blue dwellings (probable service structures), brown dwellings (probable of local material), tukuls, and large buildings/tents (service structures, area $>50 \mathrm{~m}^{2}$ ). In total, 8,045 dwellings were extracted in Kule, 5,699 dwellings in Tierkidi, and 494 dwellings outside the camps. For the areas Renk and Paloich no indication on displaced people was found.

The results of the analyses were provided as geospatial PDF maps and Google KML Maps (including legend, logo, and satellite image streamed via ArcGIS Server). For Minkaman, GIS data layers were additionally requested for further integration in own map products of the users. 


\subsection{Validation of Results}

The dwelling extraction results of Kule and Tierkidi were compared to results of outreach data, which were available for camp zones (note: camp zones did not cover the whole camp area). The outreach revealed that many shelters are currently not inhabited, and that there are many shops and commercial structures similar to shelters. Overall, there is a very good correlation of the total numbers for both camps, but for Kule there are quite large variations between the camp zones (see table 2). Interestingly, none of the results per zone showing the highest values in an alternating structure between the two approaches show a trend of clear over- or underestimation. This can be explained by unclear assignment of dwellings to camp zones during the outreach: "Physical boundaries of the camp zones are rather fluid, particularly zones $A / B$ and zones $F / G,[\ldots]$ and outreach workers often have difficulties distinguishing these zones from each other"(report epidemiologist). For Tierkidi, no spatial data representing camp zones were available which could be linked to the zones reported in the outreach assessment. Therefore we could only compare absolute numbers.

Table 2: Comparison of household estimates based on satellite images vs. outreach counts in Kule (left) and Tierkidi (right)

\begin{tabular}{|c|c|c|c|c|c|}
\hline \multicolumn{3}{|c|}{ Kule } & \multicolumn{3}{|c|}{ Tierkidi } \\
\hline Zone & $\begin{array}{l}\text { Image } \\
\text { Analysis }\end{array}$ & Outreach & Zone & $\begin{array}{l}\text { Image } \\
\text { Analysis }\end{array}$ & Outreach \\
\hline A & 877 & 1331 & A & \multirow{4}{*}{$\begin{array}{l}\text { no spatial } \\
\text { data on camp } \\
\text { zones avail- } \\
\text { able }\end{array}$} & 1845 \\
\hline B & 1119 & 509 & B & & 2008 \\
\hline $\mathrm{C}$ & 674 & 698 & $\mathrm{C}$ & & 665 \\
\hline $\mathrm{D}$ & 1407 & 499 & $\mathrm{D}$ & & 400 \\
\hline $\mathrm{E}$ & 838 & 839 & & & \\
\hline $\mathrm{F}$ & 627 & 977 & & & \\
\hline $\mathrm{G}$ & 1270 & 1397 & & & \\
\hline Total & 6812 & 6250 & Total & 5466 & 4918 \\
\hline
\end{tabular}

Dwellings within both camps have also been mapped by the Missing Maps Project in OpenStreetMap, based on the same satellite image. For Kule, the results are quite similar, whereas for Tierkidi there are indications that some areas within the camp were not mapped by OSM users, making it difficult to consider this data set for validation.

A true accuracy assessment, with reference field data collected concurrently to the analysis, like the example of Kule and Tierkidi, is often not feasible. Results from automated analyses are therefore often compared to independent visual interpretations of the image data (SPRÖHNLE et al. 2014). These interpretations depend on the skills of the interpreter, and cannot be considered as actual 'ground truth' data. Nevertheless, visual image interpretation is currently used to remove falsely detected dwellings from the automated results and include omitted dwellings. For detailed statistics we developed a tool for spatially explicit, object-based accuracy assessment. Comparing the results from the automated analysis and the manual refinement provides valuable information on the reliability of our method, tendencies of the approach for over- or underestimations, and especially the dwelling-type 
specific assessment clearly shows the strengths, but also the weaknesses of the automated analysis. These results help steadily improve the described automated approach. The tool was applied for Minkaman (4N, see table 1) to compare both the automated results and the manually refined results, as well as the automated results with figures from UNOSAT, derived from a satellite image of 03 July 2014. The comparison of the absolute dwelling numbers from the UNOSAT data and the automated results from OBIA show a high agreement, with nearly $94 \%$. The site-specific accuracies are affected by an irregular shift, induced by image pre-processing (projection and orthorectification). The site-specific results are therefore lower, with $72 \%$ matching dwellings. Comparing the overall number of automated dwelling extraction with the visually refined results, the automated analysis underestimates the amount of dwellings by $5 \%$ (see table 3 ). Only for the class dark $d$ wellings there is a difference of more than $55 \%$ between automated and manually refined results. This dwelling type has only little contrast to its surroundings, and is therefore difficult to be extracted automatically. As the request was time-critical, leaving little time for ruleset adaptation, and as this dwelling type accounted for less than $5 \%$ of all dwellings, it was decided to mainly classify these dwellings during manual refinement. While the overall user's and producer's accuracies, with almost $90 \%$ and $85 \%$, respectively, are satisfying, the accuracies of dark dwellings, tukuls, and small structures are quite low (see table 3). The class dark dwellings revealed by far the lowest producer's and user's accuracies, which means that not only the majority of dwellings were omitted during classification, but also that the objects classified as dark dwellings often turned out to be falsely classified. Looking at the areal statistics, almost $60 \%$ of the area of large structures (area $>50 \mathrm{~m}^{2}$ ) was falsely classified. This overestimation of the area is caused by some large misclassified cloud objects and objects at the image margins, which have not been eliminated during automated classification.

Table 3: Accuracy of spatially explicit dwellings and dwelling areas for the automated results from Minkaman (22 June 2014) compared to manually refined results

\begin{tabular}{|l|l|l|l|l|l|l|l|}
\hline Dwelling Type & $\begin{array}{l}\text { All (non } \\
\text { type-specific) }\end{array}$ & $\begin{array}{l}\text { Bright } \\
\text { dwell. }\end{array}$ & $\begin{array}{l}\text { Small } \\
\text { struct. }\end{array}$ & Tukuls & $\begin{array}{l}\text { Dark } \\
\text { dwell. }\end{array}$ & $\begin{array}{l}\text { Large } \\
\text { struct. }\end{array}$ & $\begin{array}{l}\text { Blue } \\
\text { dwell. }\end{array}$ \\
\hline Correctly extracted [No] & 11,625 & 9116 & 977 & 711 & 126 & 279 & 170 \\
\hline Producer's accuracy [\%] & 85.05 & 93.76 & 61.22 & 61.13 & 20.10 & 77.50 & 85.43 \\
\hline User's accuracy [\%] & 89.75 & 96.76 & 64.66 & 60.25 & 45.32 & 77.29 & 85.43 \\
\hline $\begin{array}{l}\text { Overall dwelling match [\%] } \\
\text { non site-specific) }\end{array}$ & 94.77 & 96.89 & 94.67 & 98.56 & 44.34 & 99.72 & 100.00 \\
\hline Area covered [\%] & 85.60 & 92.88 & 64.69 & 59.31 & 20.81 & 84.08 & 83.22 \\
\hline Area overestimated [\%] & 26.84 & 2.86 & 34.82 & 37.09 & 44.08 & 60.49 & 11.77 \\
\hline Area underestimated [\%] & 14.40 & 7.12 & 35.31 & 40.69 & 79.19 & 15.92 & 16.78 \\
\hline
\end{tabular}




\section{Conclusions and Outlook}

The presented examples showed that important mission-critical information for refugee/IDP camps can be provided by VHR data. Humanitarian aid workers can save critical time and resources (staff, logistics and cost) if rumours about displaced people at specific locations can be falsified when aid workers do not have to access these areas. Especially during the emergency phase it is difficult to obtain reliable population figures. Information on dwelling numbers and spatial distribution can therefore support planning of logistical infrastructure and basic services within a camp. In Minkaman, the results of dwelling extraction were used to plan the medical interventions for the entire camp - basic health care, mobile clinics, and vaccination programs. The analyses were also utilized to get a better understanding of the camp, and the needs of the population in regard to water supply and sanitation - e.g. provision of sufficient water distribution points in the various parts of the camp. The monitoring helped medical services to be available to the entire population, and to adapt the number of mobile clinics to the development of the camp. In the case of Melut, the amount of dwellings was combined with ground information available on average family size. The team was able to get a better understanding of the number of people living in the camp. This information greatly aided the planning of medical activities, as well as the distribution of relief materials. In Kule and Tierkidi the analyses supported the planning of medical activities related to the outbreak of Hepatitis E, as well as the epidemiological monitoring of the outbreak. The requests during the emergency phase, especially in the onset of the construction phase of a camp, are often very time-critical. Automated image analysis methods can improve the time frame of analysis if large numbers of features have to be extracted. They are still limited for complex dwelling types (e.g. with little contrast to surroundings), and need to be scaled according to the camp situation. Results from accuracy assessment suggest improving the rule-sets for such complex dwelling types, or relying more on manual refinement. It depends on the amount of these dwellings, e.g. if they account for less than $5 \%$ it's much faster to classify them manually. Although automated methods improve the analysis time, the highest dependency on providing up-to date information is still on data availability.

\section{Acknowledgements}

The presented work was co-funded by the Austrian Research Promotion Agency (FFG) under the Austrian Space Application Programme (ASAP) within the project EO4HumEn (contract no: 840081). Direct funding was received by Médecins Sans Frontières (MSF) Austria and the Karl Kahane Foundation. The tools on object-based post-processing and object-based accuracy assessment were co-funded by the European Commission (EC) within the FP7 project G-SEXTANT (contract no. 312912).

\section{References}

BLASCHKE, T. (2010), Object based image analysis for remote sensing. ISPRS Journal of Photogrammetry and Remote Sensing, 65, 2-16. 
FÜREDER, P., TIEDE, D., LÜTHJE, F. \& LANG, S. (2014), Object-based dwelling extraction in refugee/IDP camps - challenges in an operational mode. South-Eastern European Journal of Earth Observation and Geomatics, 3 (2S), 539-544.

LANG, S., Tiede, D., HÖlbling, D., FÜREDER, P. \& ZeIL, P. (2010), Earth observation (EO)based ex post assessment of internally displaced person (IDP) camp evolution and population dynamics in Zam Zam, Darfur. International Journal of Remote Sensing, $31(21), 5709-5731$.

Spröhnle, K., Tiede, D., Schoepfer, E., Füreder, P., Svanberg, A. \& Rost, T. (2014), Earth Observation-Based Dwelling Detection Approaches in a Highly Complex Refugee Camp Environment - A Comparative Study. Remote Sensing, 6 (10), 9277-9297.

Tiede, D., Füreder, P., LANG, S., Hölbling, D. \& ZeIL, P. (2013), Automated Analysis of Satellite Imagery to provide Information Products for Humanitarian Relief Operations in Refugee Camps - from Scientific Development towards Operational Services. PFG Photogrammetrie - Fernerkundung - Geoinformation, 3/2013, 185-195.

Tiede, D., LANG, S., Hölbling, D. \& FÜreder, P. (2010), Transferability of OBIA rulesets for IDP Camp Analysis in Darfur. In: AdDink, E. A. \& Colllie, F. M. B. van (Eds.), GEOBIA 2010 - Geographic Object-Based Image Analysis, Ghent University, Ghent, Belgium, 29 June - 2 July. ISPRS Vol. XXXVIII-4/C7, Archives, ISSN 1682-1777.

UN High COMmissioner FOR REFugeES (UNHCR) (2014), South Sudan. 2015 UNHCR country operations profile - South Sudan. http://www.unhcr.org/pages/4e43cb466.html (22 January 2015). 